\title{
FY00 LDRD Final Report High Power IFE Driver Component Development SI-009
}

K. Schaffers, C. Bibeau, J. Tassano, P. Waide, A. Bayramian, S. Payne

February 26, 2001

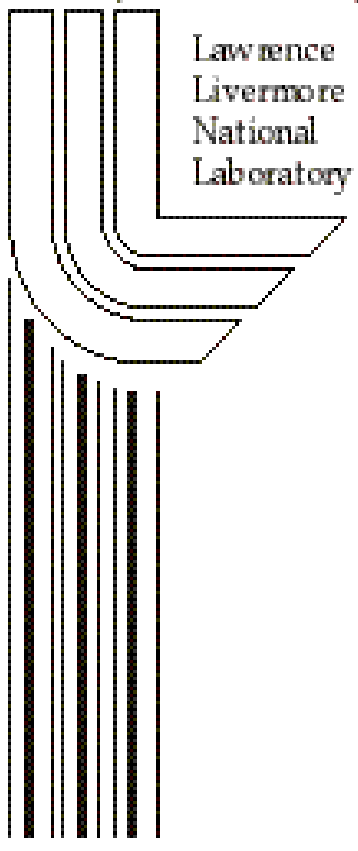




\section{DISCLAIMER}

This document was prepared as an account of work sponsored by an agency of the United States Government. Neither the United States Government nor the University of California nor any of their employees, makes any warranty, express or implied, or assumes any legal liability or responsibility for the accuracy, completeness, or usefulness of any information, apparatus, product, or process disclosed, or represents that its use would not infringe privately owned rights. Reference herein to any specific commercial product, process, or service by trade name, trademark, manufacturer, or otherwise, does not necessarily constitute or imply its endorsement, recommendation, or favoring by the United States Government or the University of California. The views and opinions of authors expressed herein do not necessarily state or reflect those of the United States Government or the University of California, and shall not be used for advertising or product endorsement purposes.

This work was performed under the auspices of the U. S. Department of Energy by the University of California, Lawrence Livermore National Laboratory under Contract No. W-7405-Eng-48.

This report has been reproduced directly from the best available copy.

Available electronically at http://www.doc.gov/bridge

Available for a processing fee to U.S. Department of Energy

And its contractors in paper from

U.S. Department of Energy

Office of Scientific and Technical Information

P.O. Box 62

Oak Ridge, TN 37831-0062

Telephone: (865) 576-8401

Facsimile: (865) 576-5728

E-mail: reports@adonis.osti.gov

Available for the sale to the public from

U.S. Department of Commerce

National Technical Information Service

5285 Port Royal Road

Springfield, VA 22161

Telephone: (800) 553-6847

Facsimile: (703) 605-6900

E-mail: orders@ntis.fedworld.gov

Online ordering: http://www.ntis.gov/ordering.htm

OR

Lawrence Livermore National Laboratory

Technical Information Department's Digital Library

http:/ / www.llnl.gov/tid/Library.html 


\section{FY00 LDRD Final Report \\ High Power IFE Driver Component Development SI-009}
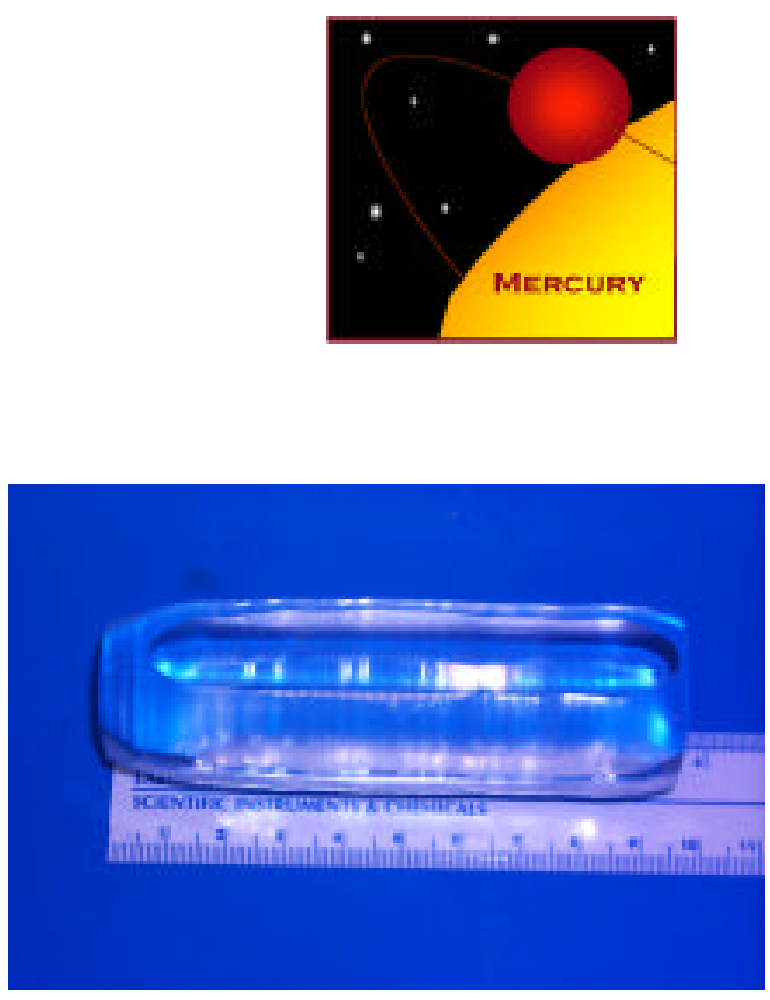

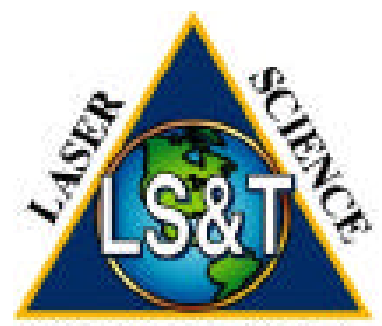

TECHNOLOGY
Principal Investigator:

Core Technical Team:

Program:

Program Leader:

Associate Program Leader: Steve Payne Lawrence Livermore National Laboratory Livermore, California 94550

February 26, 2001

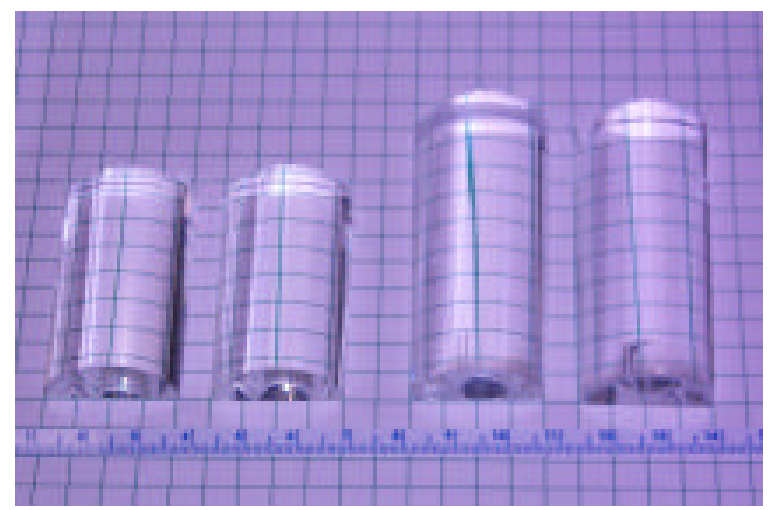

Camille Bibeau

Kathleen Schaffers, John Tassano, Phil Waide, Andy Bayramian

Laser Science and Technology

Lloyd Hackel 


\section{Focus of Report}

We have begun building the "Mercury" laser system as the first in a series of new generation diode-pumped solid-state lasers for target physics research. Mercury will integrate three key technologies: diodes, crystals, and gas cooling, within a unique laser architecture that is scalable to kilojoule and megajoule energy levels for fusion energy applications. The primary near-term performance goals include $10 \%$ electrical efficiencies at $10 \mathrm{~Hz}$ and $100 \mathrm{~J}$ with a 2-10 ns pulse length at $1.047 \mu \mathrm{m}$ wavelength. Currently, this review concentrates on the critical development and production of Yb:S-FAP crystals. After solving many defect issues that can be present in the crystals, reproducibility is the final issue that needs to be resolved. We have enlisted the help of national experts and have strongly integrated two capable commercial crystal growth companies (Litton-Airton/Synoptics and Scientific Materials) into the effort, and have solicited the advice of Robert Morris (retired from Allied Signal), a recognized international expert in high temperature oxide growth.

\section{Background}

The ultimate goal of ICF is to build a power plant based on laser fusion [1]. Gas-cooled diodepumped Yb-crystal lasers are envisioned to be the next-generation ICF solid-state laser system. NIF and the advanced diode-pumped solid state lasers (DPSSLs) share a great deal of common features, especially with regard to fundamental issues: multi-pass amplifiers, laser propagation, energy storage, extraction, pumping, linear and nonlinear wavefront distortions, frequencyconversion, and beam-smoothing. The DPSSL approach builds on the last two decades of ICF solid state laser development but also adds several imposing challenges-repetition rate, many shot reliability, and cost. Flashlamp-pumped solid-state lasers built for ICF studies have been optimized for the $\$ /$ Joule figure-of-merit and for their ability to match the target requirements. They are inherently single-shot devices, requiring several hours to recover from thermal distortions. The goal of developing ICF lasers with high repetition rate and efficiency is only now beginning to be addressed. Solutions to these issues are:

- Employing near-sonic gas cooling for the laser slabs

- Trading the flashlamps for low-cost, large-size laser diode arrays

- Using Yb:crystals with greater energy storage and thermal conductivity than $\mathrm{Nd}$ :glass

The Mercury Laser (Figure 1) is the first step in integrating these new approaches, and in producing new capabilities for irradiating targets. The primary performance goals for the Mercury Laser are:

- $10 \mathrm{~Hz}$ repetition rate

- $10 \%$ efficiency

- $1.047 \mu \mathrm{m}$ wavelength $(1 \omega)$
- 100 Joules energy @2-10 ns

- 5x diffraction-limited beam quality

- $10^{7}$ shot lifetime

When completed, Mercury will be the highest energy/pulse diode-pumped laser ever built by an order of magnitude. It is noteworthy that the $100 \mathrm{~J}$ energy is the same as that of the Janus Laser, which is based on flashlamp-pumped Nd:glass and originally built in 1973, implying that DPSSLs for ICF are just in their infancy. In addition, the Mercury Laser will be upgradable to $3 \omega$ generation, broad bandwidth for beam smoothing, and picosecond pulse operation. 
Great progress has been made in all of the technologically challenging areas of the Mercury Laser. However, this SI was exclusively directed at the critical development of the Yb:crystals for Mercury.
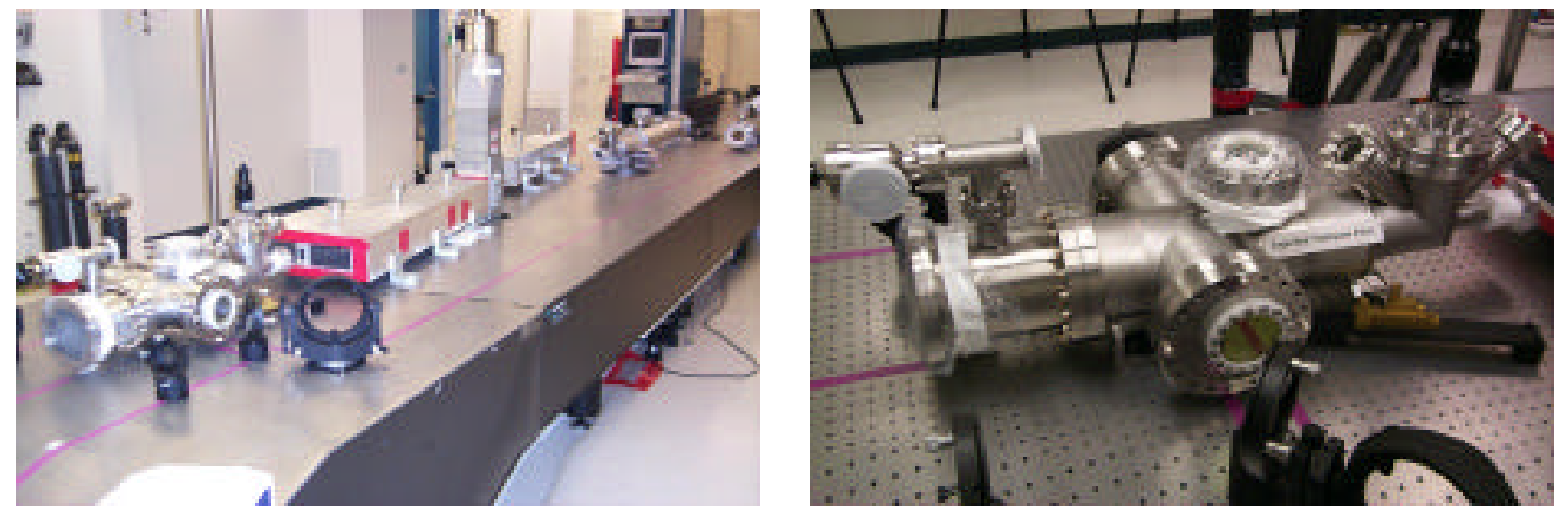

Figure 1. Pictures of the Mercury Laser, which is currently being used to experimentally test laser system components.

\section{Progress in the crystal growth of Yb:S-FAP}

\section{A. Growth Methodology}

The goals of the crystal growth effort are to produce high quality Yb:S-FAP $\left[\mathrm{Yb}^{3+}: \mathrm{Sr}_{5}\left(\mathrm{PO}_{4}\right)_{3} \mathrm{~F}\right]$ crystals; this involves developing an outside company resource for the growth of full size crystals and assessing the feasibility of bonding smaller crystals together to produce full aperture crystals with no compromise to the optical quality. The Mercury design requires crystalline slabs of dimension $4 \times 6 \times 0.75 \mathrm{~cm}$, Fig. 1, which will be potted into vanes and mounted into two amplifier heads; seven slabs will be required for each head. The growth of full aperture crystals has been a challenge due to a number of defects, including: cloudiness in asgrown boules, bubble core defects, grain boundaries, anomalous absorption, cracking, and small inclusions around the outside of the boules. There are now three Czochralski growth stations dedicated to the growth effort, chillers have been added to control cooling water temperatures to the power supplies thus regulating the heat load and a motor generator has been installed to damp out fluctuations in the incoming power to the power supplies. 


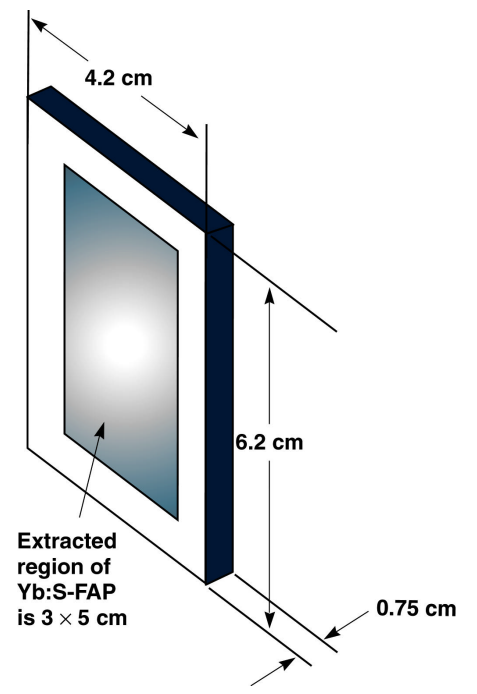

Fig. 2. Schematic of the slab dimensions required for the Mercury design.

Significant progress has been made in understanding the growth characteristics and defect chemistry of $\mathrm{Yb}$ :S-FAP crystals. In an effort to fully understand and eliminate the defect issues in Yb:S-FAP and develop a feasible growth technique for producing high optical quality crystals, a collaborative research effort has been initiated within LLNL and among experts in the high temperature crystal growth community: (1) Dr. Robert C. Morris (formerly of Allied Signal Corporation) who is a world-renowned leader in growth and solving defect problems in optical crystals, has been participating as a consultant, (2) Robert S. Feigelson of Stanford University has provide valuable technical insight and expertise, (3) Ralph Hutcheson at Scientific Materials (Bozeman, MT) has investigated the growth of Yb:S-FAP in various thermal geometry furnace designs to determine the effects on crystal quality (described in more detail below), and (4) the Litton-Airtron/Synoptics Group team of growth, materials, and analysis experts have been engaged via a growth contract to participate in solving the defect issues and growing high optical quality crystals for use as laser slabs. An advantage of working with Litton is that they have a proven facility in place for solving defect issues and growing high quality crystals of the dimension needed for Mercury and the next generation lasers.

\section{Growth Process}

Crystals of Yb:S-FAP are grown by using the Czochralski method in three growth stations, one of which is shown in Fig. $2 a$, along with a schematic of the current furnace design and basic growth parameters, Fig. $2 b$. The growth station consists of a Czochralski crystal puller, a $25 \mathrm{kWatt}$ induction power supply, and a computer program that is used for controlling the diameter of the crystal. A 4" diameter by 4" tall Iridium crucible is used to contain the melt because it does not chemically react with Yb:S-FAP, it has a high melting point, and the 4" size is conducive to maintaining the appropriate thermal conditions in the melt during growth. 

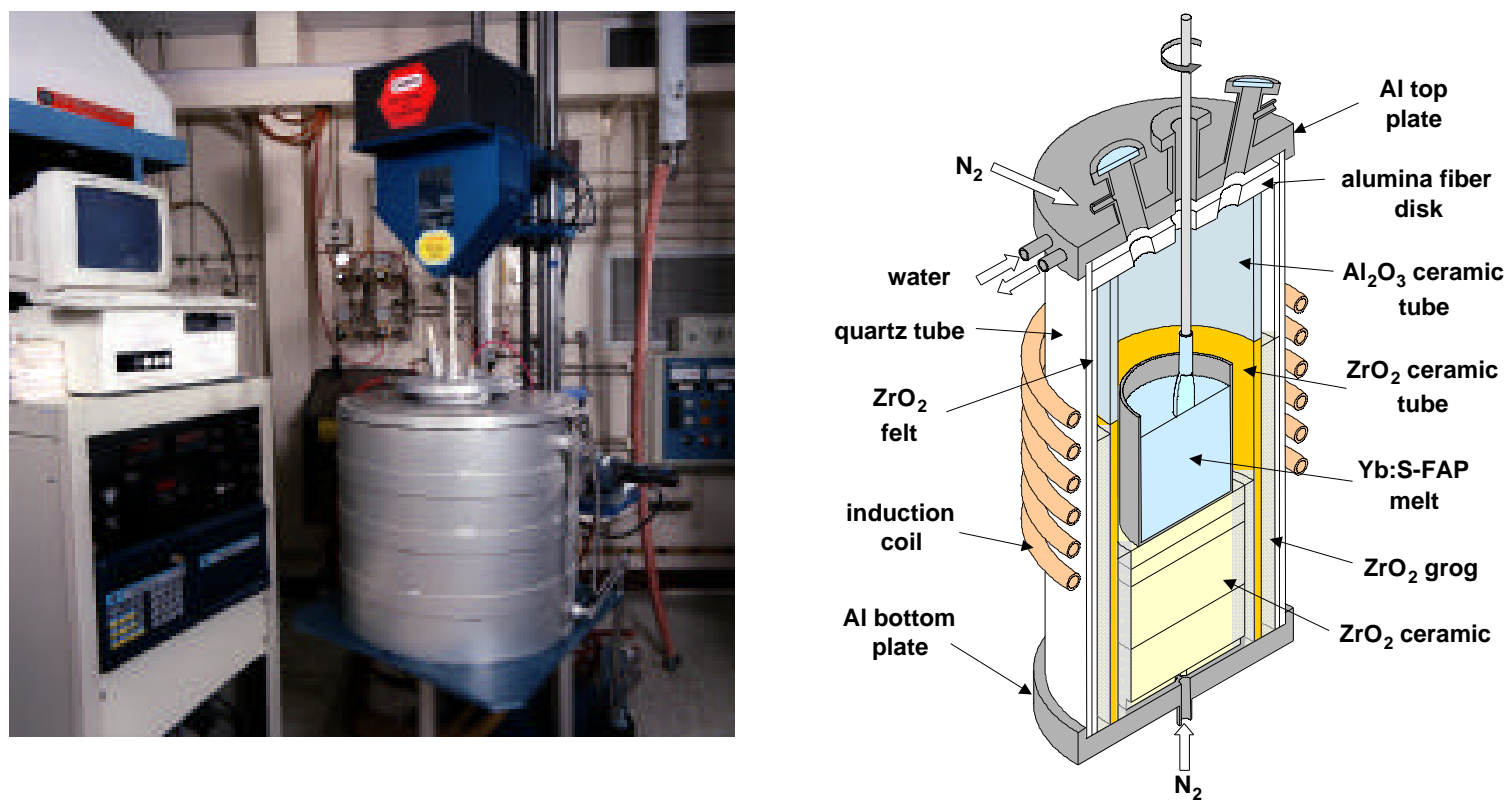

Fig. 3. (a) Picture of a Czochralski crystal growth station used for Yb:S-FAP growth. (b) Schematic of the current furnace design with approximate growth parameters.

Crystal growth is done at $1800^{\circ} \mathrm{C}$, in an inert, flowing nitrogen atmosphere with rotation rates of approximately $15 \mathrm{rpm}$ and a pull rate of $0.5 \mathrm{~mm} / \mathrm{hr}$. As described later, excess $\mathrm{SrF}_{2}$ in the melt has been chosen because it produces clear crystals with no cloudiness. The melt is prepared by decomposing $\mathrm{SrHPO}_{4}, \mathrm{SrCO}_{3}$, and $\mathrm{Yb}_{2} \mathrm{O}_{3}$ starting materials to yield a $\mathrm{Yb}$-doped $\mathrm{Sr}_{3}\left(\mathrm{PO}_{4}\right)_{2}$ melt to which $\mathrm{SrF}_{2}$ is added to make the appropriate composition. The predecomposition reaction prevents $\mathrm{SrF}_{2}$ from oxidizing to $\mathrm{SrO}$ thereby removing fluoride from the melt. $\mathrm{Yb}_{2} \mathrm{O}_{3}$ has been typically used as the dopant to aid in the charge compensation process where a $\mathrm{Yb}^{3+}-\mathrm{O}^{2-}$ ion pair exchanges for a $\mathrm{Sr}^{2+}-\mathrm{F}^{1-}$ pair.[2] An excess of $\mathrm{Yb}_{2} \mathrm{O}_{3}$ is added to the starting composition to accommodate the approximate $12 \%$ distribution coefficient from the melt to crystal; ie., only $\sim 12 \%$ of the $\mathrm{Yb}$ that is put into the melt composition incorporates into the crystal that is grown, so excess is necessary to get the appropriate doping level in the crystal.

The time required for the current growth geometry of $\mathrm{Yb}$ :S-FAP crystals is approximately 16 days and encompasses a series of four steps critical to controlling the defect issues, Fig. 3. First, a seed extension is grown to aid in propagating the initial defects out toward the sides of the crystal where they will terminate. A small cone angle, or gentle increase in diameter, is necessary since the growth rates are higher in this section and defects can form from instabilities. In the cylinder section of the crystal, the ability to maintain stable growth conditions is essential to prevent defect initiation or propagation. Finally, the crystal is necked in at the bottom and cooled while still attached to the melt so that the large thermal mass of the melt effectively lowers the thermal gradients along the length of the crystal during the cooling process.

Current boule dimensions are 2.9-3.4 $\mathrm{cm}$ diameter by $8 \mathrm{~cm}$ length grown along the c-axis. Efforts have been centered on growing crystals of sufficient size to produce half-slabs for diffusion bonding to form the full size 4 × 6 x $0.75 \mathrm{~cm}$ full slab needed for Mercury. 


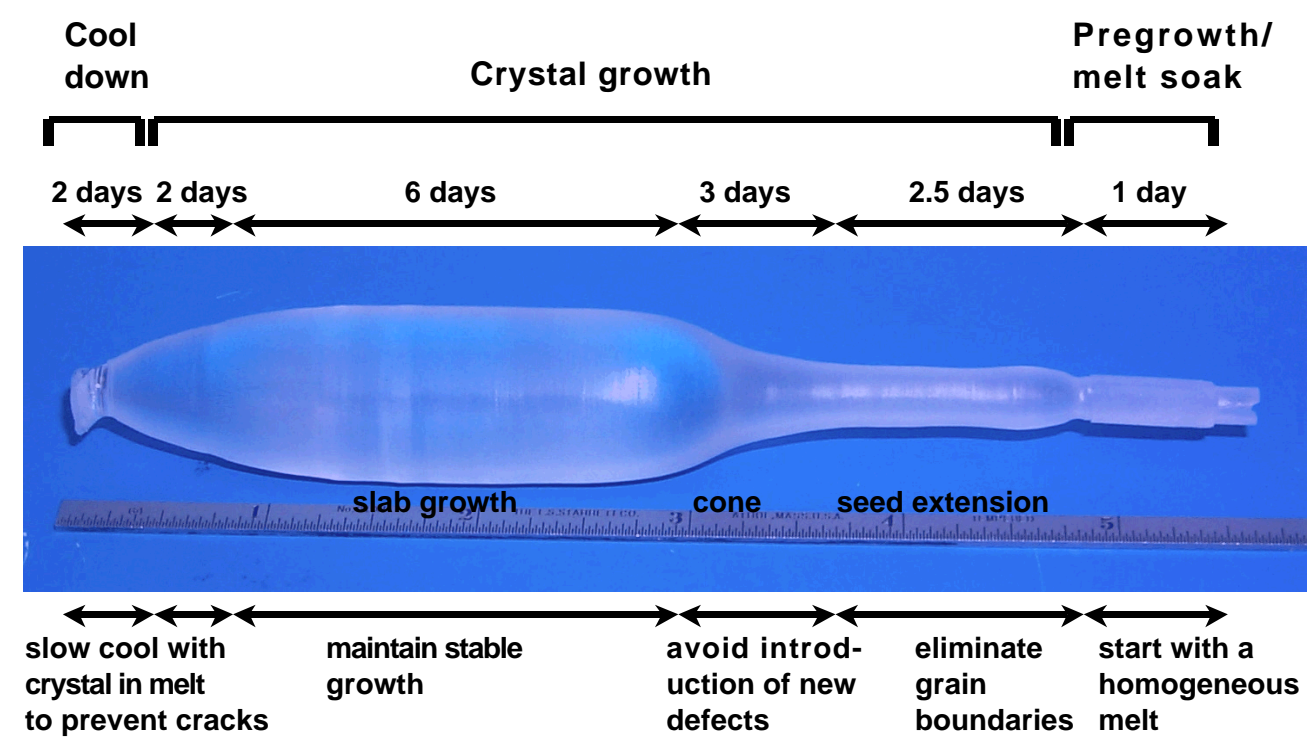

Fig. 4. Current technique for the growth of Yb:S-FAP crystals.

\section{Improvements}

Over the last year, several improvements have been implemented to increase the ability to reproducibly grow high optical quality $\mathrm{Yb}$ :S-FAP crystals. Water recirculation chillers were added to the power supplies to damp out fluctuations in cooling water temperature, which causes ridges on the crystals due to instabilities at the growth interface. This instability is a source of defect formation and therefore a critical variable to control. In addition, a motor generator has been installed for filtering power on the incoming supply line that feeds into the induction power supplies (Fig 4). The power stability increases the ability to control the growth interface preventing defects, decreases the number of crystal growth failures from power surges and drops, and most important, has allowed for reproducibility from one growth run to the next for the first time in the crystal growth facility. Also, three furnaces have been dedicated to the growth and development of $\mathrm{Yb}$ :S-FAP crystals so that a growth process to control all of the defects could be found more quickly.
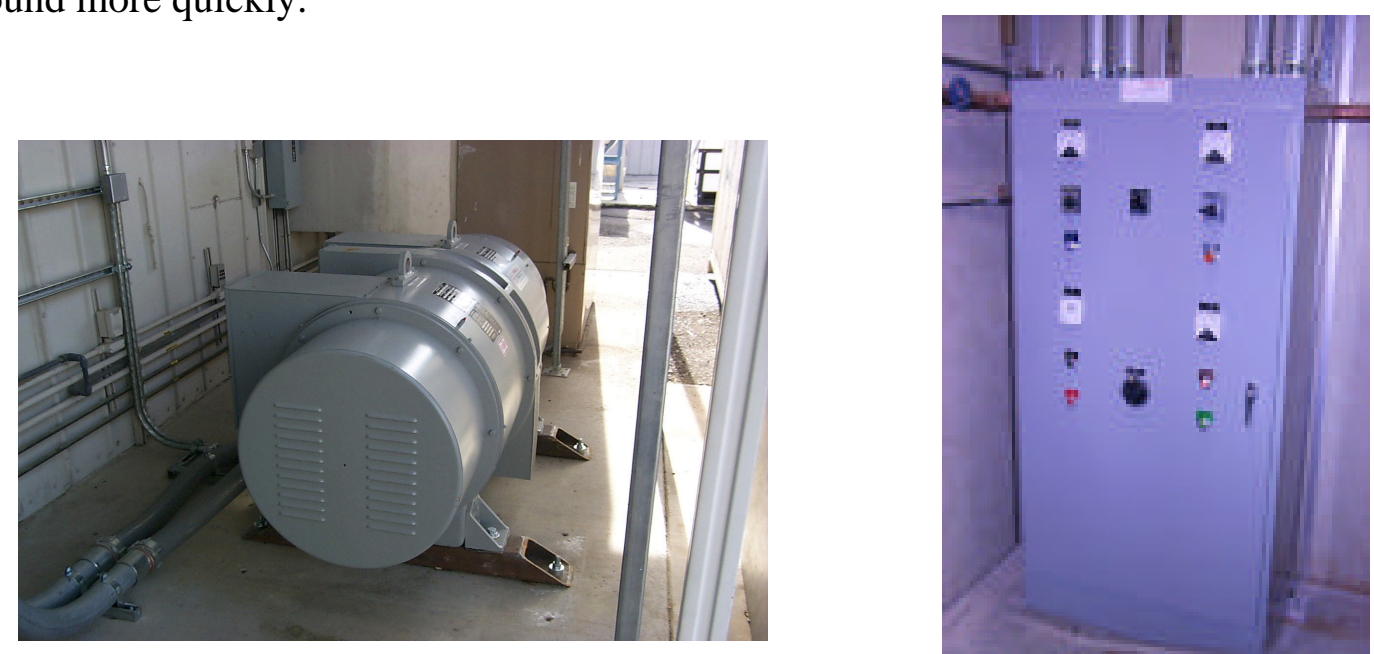

Fig. 4. Pictures of the installed motor generator and control panel used for power conditioning. 


\section{B. Defect Chemistry and Growth Strategies}

A number of defect structures are present in Yb:S-FAP crystals and must be overcome to produce high quality material for laser slabs. The six prominent defects encountered are cloudiness in as-grown boules, bubble core defects, low-angle grain boundaries, anomalous absorption, cracking, and scattering inclusions around the outside of the boules (Fig 5). An understanding of these defects has been achieved in an effort to engineer methods to eliminate or sufficiently reduce their magnitude to lessen the effect on laser performance.

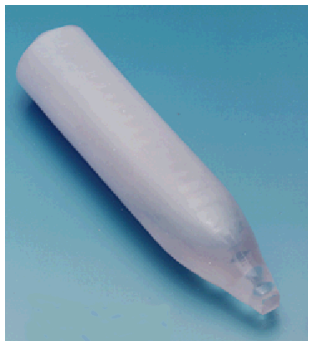

(a)Cloudiness

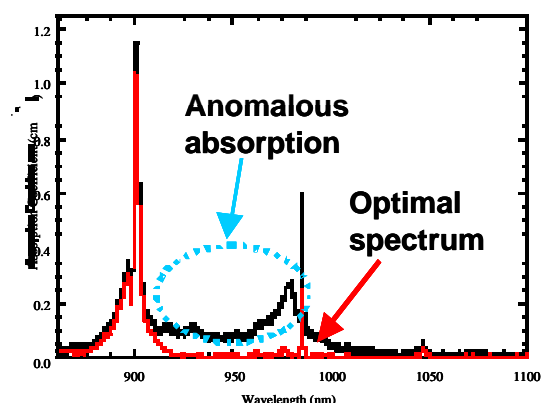

(b)Anomalousabsorption (c) Grain boundaries

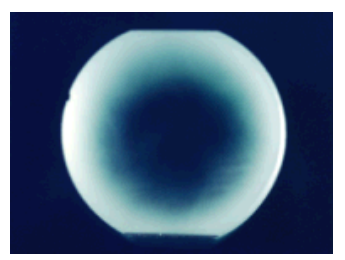

(e) Cracking 。

(f) Scattering inclusions

Fig. 5. The six prominent defects in Yb:S-FAP crystals are shown, (a) cloudiness, (b) anomalous absorption, (c) grain boundaries, (d) bubble core, (e) cracking, and (f) scattering inclusions.

\section{Cloudiness}

A $\mathrm{SrF}_{2}$-rich melt composition has proven effective in eliminating the cloudiness in boules of Yb:S-FAP grown from a near-stoichiometric melt, Fig. 5a. The cloudiness is believed to be a result of second-phase particles that precipitate out in the crystal lattice. The identity of the second phase has not yet been verified, but it is likely of phosphate-based origin resulting from a deficiency of $\mathrm{SrF}_{2}$ at the growth interface with the evaporation from the melt surface. As a result, an excess of $\mathrm{SrF}_{2}$ beyond the stoichiometric composition is added to yield 33 mole percent total fluoride in the melt and clear crystals are grown. It has been found that the amount of excess $\mathrm{SrF}_{2}$ that is added is significant where $<33 \mathrm{~mol} \%$ yields cloudy crystals and large excesses lead to the formation of new, long "string-type" defects that propagate perpendicular to the c-axis at the core. However, compositions near $33 \mathrm{~mol} \%$ are optimal for eliminating the 
supersaturation of the second phase and clear crystals are produced. A partial phase diagram has been completed by NIST (National Institute of Standards and Technology) and there is an indication that a congruent melting composition of $28 \mathrm{~mol} \% \mathrm{SrF}_{2}$ may exist, however, excess $\mathrm{SrF}_{2}$ is likely needed to accommodate the vaporization of $\mathrm{SrF}_{2}$ from the melt during growth. Further study of the phase diagram is being done to identify the exact phase relationships that give rise to the clear crystals grown from the $33 \mathrm{~mol}^{2} \mathrm{SrF}_{2}$ melt composition.

\section{Anomalous absorption}

A growth orientation along the c-axis for $\mathrm{Yb}$ :S-FAP crystals has proven helpful for eliminating the anomalous absorption that occurs as a broad band from approximately 925-1000 $\mathrm{nm}$ with a peak at $975 \mathrm{~nm}$, Fig. 5b. Crystals grown along both the a-axis and $45^{\circ}$ to the c-axis intermittently display the unwanted absorption whereas this absorption is rarely detected in the caxis boules that have been grown to date. The absorption is attributed to the $\mathrm{Yb}^{3+}$ ion in a second site in the crystal lattice, based on excitation and emission spectra. The spectrum most closely resembles that of $\mathrm{Yb}^{3+}$ in a phosphate environment such as is seen in $\mathrm{LuPO}_{4}$ [3], where there are no characteristics of the desired spectrum arising from the vibration interactions of the $\mathrm{Yb}^{3+}-\mathrm{O}^{2-}$ charge compensation pair. [2] A possible explanation for the rarity of the anomalous absorption in c-axis crystals relates to the presence of $\mathrm{F}^{-}$ion "conduction" channels that parallel the c-axis in the apatite lattice. The preferred orientation may allow for easier charge compensation substitution of the $\mathrm{Yb}^{3+}-\mathrm{O}^{2-}$ pair for the $\mathrm{Sr}^{2+}-\mathrm{F}^{-}$pair, giving rise to the appropriate absorption spectrum thereby reducing the probability of $\mathrm{Yb}$ achieving charge compensation by another mechanism.

\section{Grain boundaries}

The growth of "seed extensions" and choice of a small cone angle to maintain a stable growth interface have eliminated low-angle grain boundaries. The grain boundaries appear as slight shifts in the refractive index or waves running through the crystal in sheets oriented perpendicular to the c-axis, Fig. 5c. It is understood that the dislocations are formed by propagation from the seed to the crystal and strain-induced deformations from an unstable growth interface. [4] The growth of a seed extension makes it possible to grow out any grain boundaries propagating from the seed or formed during the seeding process. In addition, a gradual increase in diameter in the cone section helps to maintain stable growth conditions reducing hoop stress and preventing new grain boundaries from forming. Further, c-axis growth makes it easier to grow out grain boundaries because they propagate perpendicular to the growth direction.

\section{Bubble core}

Crystals of Yb:S-FAP are grown in a higher thermal gradient furnace and at small 2-3 cm diameter to stabilize the growth interface and control the formation of bubble core defects, Fig $5 \mathrm{~d}$. The bubble core is attributed to constitutional supercooling where a supercooled liquid is formed from concentration gradients of rejected melt components pushed along in front of the advancing interface. In the $\mathrm{Yb}: \mathrm{S}$-FAP system, $\mathrm{SrF}_{2}$ and $\mathrm{Yb}_{2} \mathrm{O}_{3}$ are in excess to alleviate cloudiness and account for the distribution coefficient of dopant, respectively, and therefore, may 
be of higher concentration near the interface after being turned away from the growing crystal. Instabilities deviating from steady-state conditions, resulting from this phenomenon can then cause small protuberances that can come in contact with the supercooled liquid and grow very fast away from the interface into the melt. Eventually these protuberances grow together and close off, trapping low melting temperature liquid, which contracts and leaves a void upon cooling. SEM/EDS analysis has pinpointed the approximate composition associated with the bubbles to be $\mathrm{Yb}_{2} \mathrm{O}_{3}$ and $\mathrm{Sr}_{3}\left(\mathrm{PO}_{4}\right)_{2}$. To prevent the growth of any protuberances formed at the interface, we have used higher thermal gradients, typically axial gradients of $35-60^{\circ} \mathrm{C} / \mathrm{cm}$ near the melt. In addition, it has been observed that the introduction of the bubble core consistently begins at diameters of approximately $\geq 3.3 \mathrm{~cm}$. Recent growths of smaller, $3.0 \mathrm{~cm}$ diameter boules, in the higher gradient have completely eliminated the bubble core defects.

\section{Cracking}

Cracking is managed by not separating the crystals from the melt during the cooling process and by significant reduction of defects. The main source of cracking is related to high thermal gradients in the crystals, especially at larger $(4 \mathrm{~cm})$ diameters, as well as numerous bubble core defects, Fig 5e. Cooling the crystals still attached to the melt reduces the thermal stress along the length of the boule by using the large thermal load of the melt to conduct heat into the crystal.

\section{Scatter inclusions}

This past year scattering inclusions developed around the outside diameter of the boules limiting the amount of usable material that can be cut from a crystal, Fig. 5f. SEM/EDS analysis of these defects indicates a high concentration of $\mathrm{Yb}$ ion and with the composition of $\mathrm{Yb}_{2} \mathrm{O}_{3}$, determined by TEM (tunneling electron microscopy). Recent growths at high thermal gradients show that the inclusion density can be forced to the outside $2.0 \mathrm{~mm}$ of the crystal, but it is believed that with the modification of the current furnace/cooling tank design of the crystal pullers, the scattering inclusions can be completely eliminated. This modified design will be implemented in the second half of FY01.

\section{Diffusion Bonding}

At this time, to reduce defects, approximate $3.4 \mathrm{~cm}$ diameter boules will be grown. This size is sufficient to harvest _-slabs that can be diffusion bonded together to form a full size $4 \times 6$ $\mathrm{x} 0.75 \mathrm{~cm}$ slab, Figure 6 . Bonding of Yb:S-FAP has been previously demonstrated by Onyx Optics in Dublin, CA, where a subscale crystal was cut in half, the refractive index core removed, and then bonded back together, Figure 7a. Interferometry techniques are used as a diagnostic tool for determining the optical quality of the Yb:S-FAP slabs. Figure 7b shows the phase map of the bonded crystal where an angular bond technique was used to gradually overlap the two sections of crystal so as not to create a step function effect in the refractive index; it is clear that the bonded regions appear not to have a measurable effect on the phase front of the crystal. These phase maps of the homogeneity of the crystal can also be converted to Power Spectral Density (PSD) plots, which are the square of the Fourier amplitude spectrum divided by 
the width of the frequency intervals. This is a common measure of optical quality used for most optical parts in the industry today. Figure 7c compares the PSD of one half of the crystal that does not include the bond to the PSD of the whole crystal including the bond. Clearly, the two PSD's show no measurable difference, thus validating this technique as an option for using subaperture crystals to produce a full-size slab.

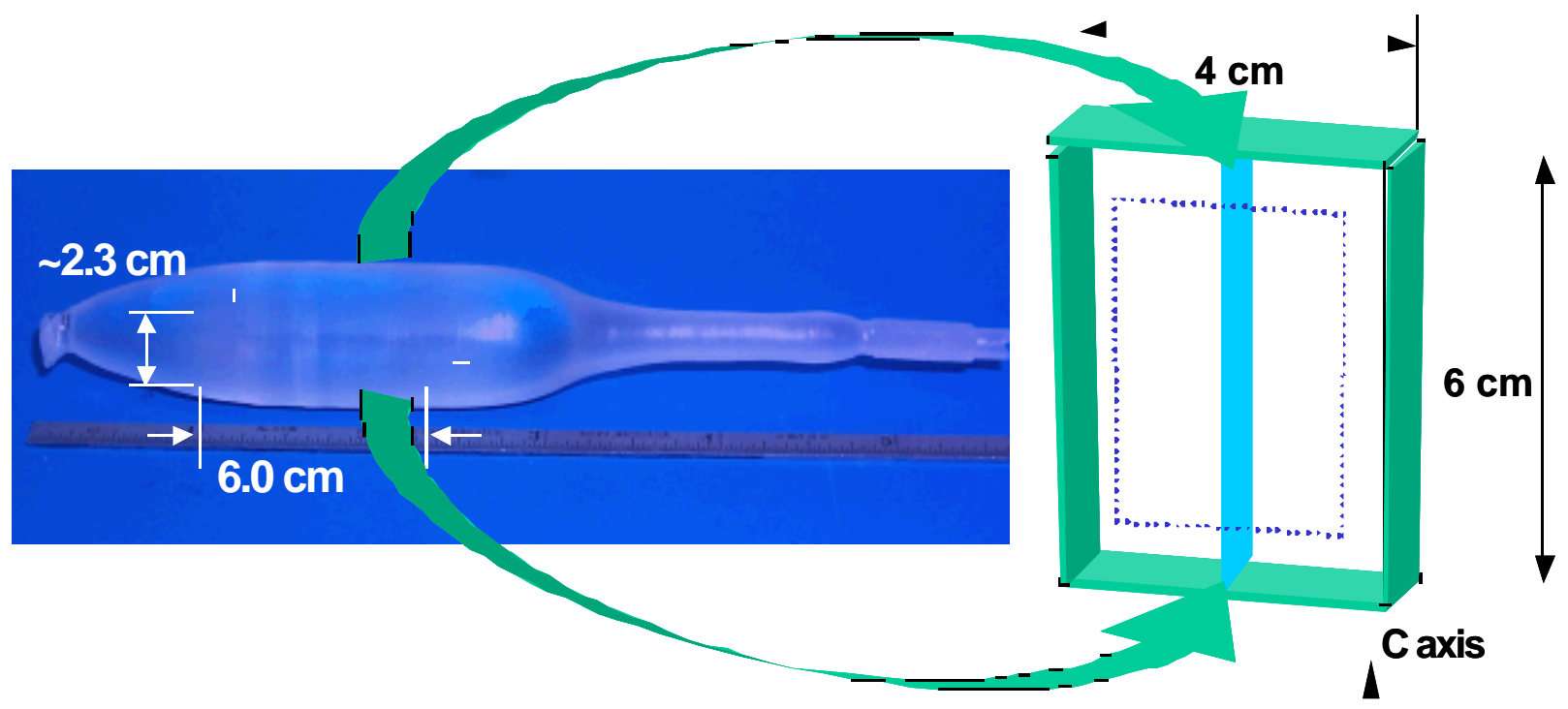

Aaxis

Figure 6. Picture of the current growth geometry of a Yb:S-FAP boule and the orientation of the slabs for diffusion bonding.
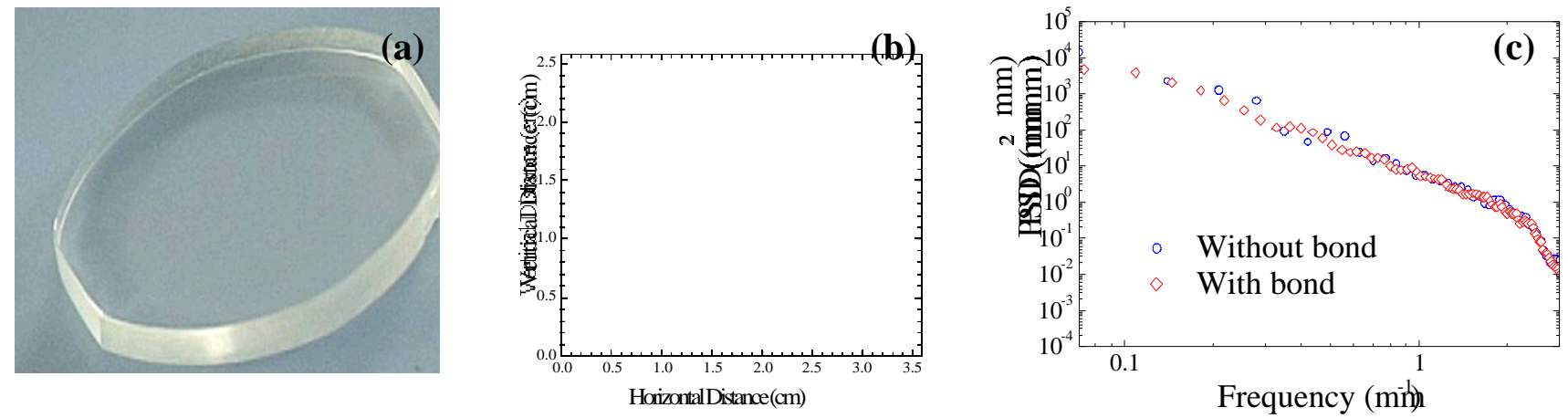

Figure 7. (a) Picture of bonded Yb:S-FAP crystal; (b) Interferogram of the bonded crystal; and (c) PSD of the comparing the crystal with the bond and without the bond. 


\section{Summary}

A reproducible growth process has been developed to nearly eliminate each of the defects encountered in $\mathrm{Yb}: \mathrm{S}-\mathrm{FAP}$ crystals. Excess $\mathrm{SrF}_{2}$ in the initial melt and c-axis growth have been successful in preventing cloudiness and the anomalous absorption. Also, seed extensions, higher thermal gradients, and small diameter crystals have proven effective in handling the formation of grain boundaries, bubble core defects, and scattering inclusions. With the significant reduction in defects together with cooling the crystals while attached to the melt, cracking is no longer an issue. Finally, a modified furnace design is being pursued to eliminate the scattering defects. Boules grown using this recipe yield high optical quality crystals that are of sufficient size to yield a half-size Mercury slab, as shown in Figure 8. Figure 9 displays a recent growth by Litton-Airtron, Synoptics Group that shows significant progress toward producing boules from which slabs can be harvested. The diffusion bonding technology will be used to stitch together two sub-slabs to form a full size $(4 \times 6 \mathrm{~cm})$ slab. The bonding process has been proven successful in test samples where there is no evidence of the bond visibly or by using interferometry (see the following section for details).

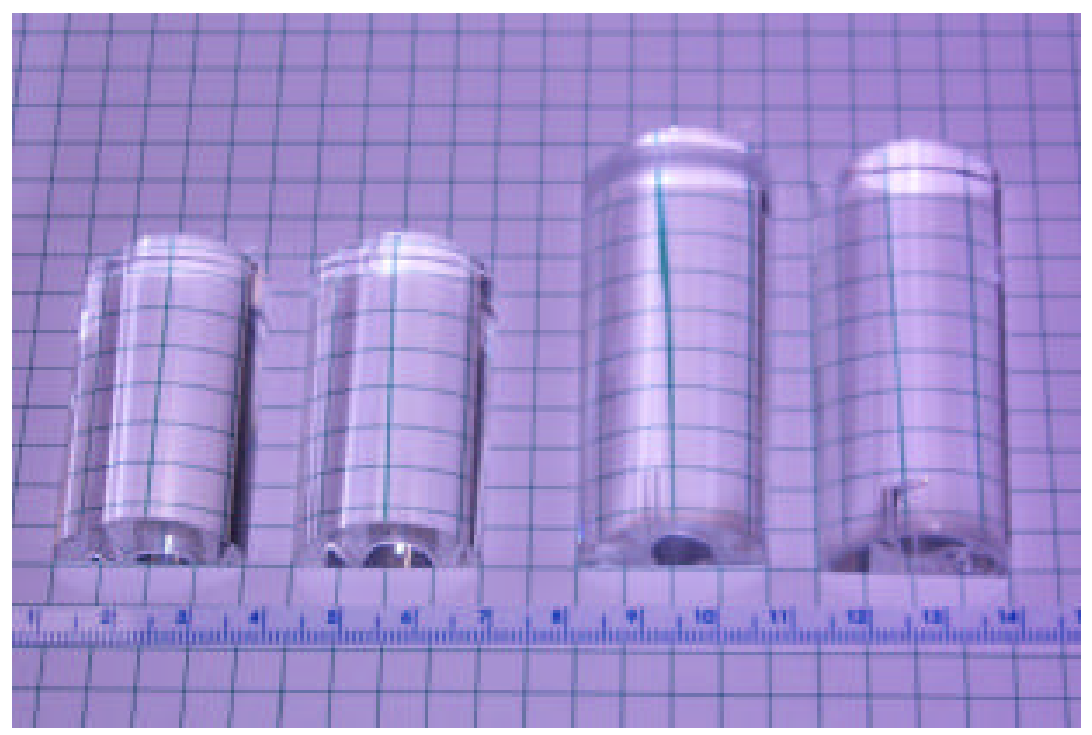

Fig. 8. Photograph of polished, high optical quality Yb:S-FAP crystals of sufficient size to yield two half-size slabs that will form a $3 \times 5 \mathrm{~cm}$ slab (grown at LLNL). 


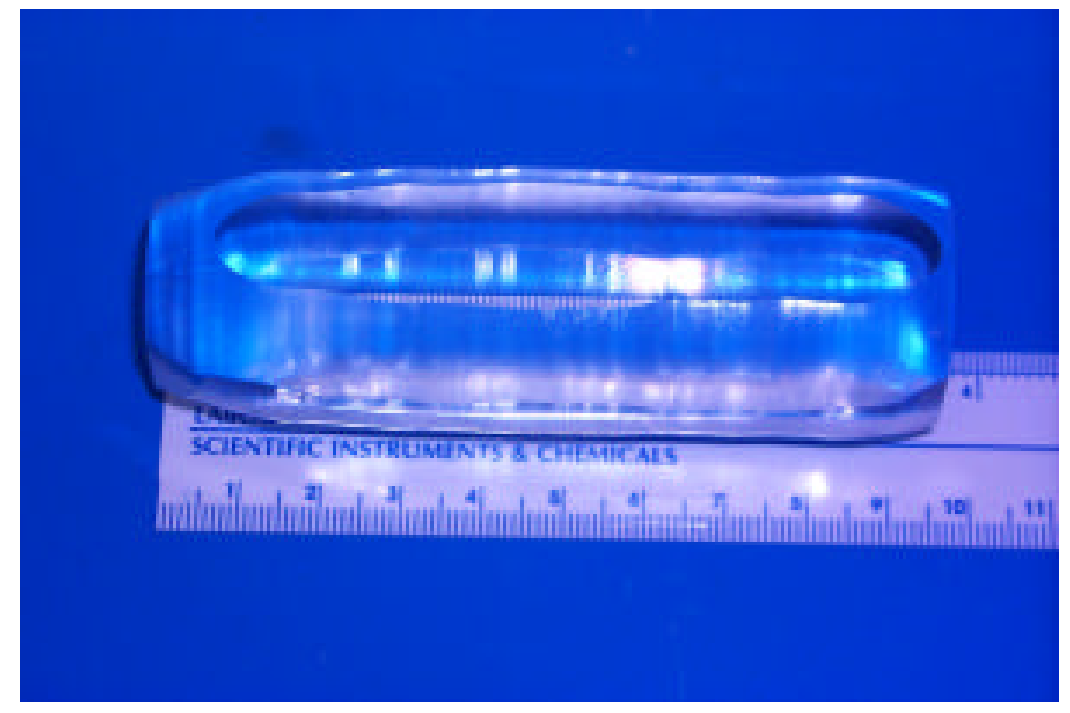

Fig. 9. Recent boule grown at Litton-Airtron/Synoptics that will yield a half size slabs large enough to form a full size 4 x $6 \mathrm{~cm}$ Mercury slab.

\section{References}

1. Mercury Laser Workshop (hosted by Institute for Laser Science and Applications) held on September 30, 1998, Livermore, CA (committee: Hector Baldis, Camille Bibeau, Chris Marshall, and Howard Powell).

2. 2. L. D. DeLoach, S. A. Payne, W. L. Kway, J. B. Tassano, S. N. Dixit, and W. F. Krupke, J. Luminescence 62 (1994) 85.

3. L. D. DeLoach, S. A. Payne, L. L. Chase, L. K. Smith, W. L. Kway, and W. F. Krupke, IEEE J. Quantum Electron. 29 (1993) 1179.

4. Private communication with Robert Morris, Consultant (1998).

*Work done under the auspices of the U.S. Department of Energy by the University of California Lawrence Livermore National Laboratory under Contract W-7405-ENG-48. 